\title{
Automated unit for magnetic pulse processing of strawberries
}

\author{
Dmitriy Khort, Alexey Kutyrev*,and Rostislav Filippov \\ Federal Scientific Agroengineering Center VIM, 1-st Institutsky proezd, 5, Moscow, 109428, Russia.
}

\begin{abstract}
The article presents the developed automated unit for magnetic pulse processing of strawberries. To maintain the required magnetic induction value in the impact zone, the unit design provides for the possibility of changing the position of the working bodies in the vertical and horizontal planes in an automated mode. The unit includes a device for magnetic pulse treatment of plants, magnetic inductors, a control unit for the system of adaptation of working bodies and a program for controlling operating modes. As a result of field studies, it was found that in order to obtain the required value of magnetic induction in the processing zone at a pulse repetition frequency from 1 to $64 \mathrm{~Hz}$ and a magnetic induction of 0.3-15 MT, it is necessary to ensure a distance between the working organs and plants from 10 to $250 \mathrm{~mm}$. The required design parameters of the unit that allow for magnetic pulse processing on strawberry plantings with a row spacing of $0.3-1.5 \mathrm{~m}$ are determined: the width of the gripper, adjustable 1.6-3.6 $\mathrm{m}$, the tilt adjustment of the working bodies in the vertical direction from 0 to 90 .
\end{abstract}

\section{Introduction}

In order to achieve a technological effect by creating the most favorable conditions for plants, research is currently being actively carried out on environmentally safe methods of exposure, effective abiotic low-energy technologies based on the use of various physical factors that can stimulate growth, increase crop yield and plant resistance to pests and diseases [1]. The analysis of the conducted studies shows the high efficiency of using a low-frequency pulsed magnetic field (IMP) of low intensity (from 0.05 to $100 \mathrm{MT}$ ), which varies in amplitude and frequency [2]. Various ways of its use for bioregulatory activation of the life processes of garden plants are proposed [3]. Practically significant effects associated with magnetic pulse treatment (MPP) of plants are characterized by improved survival of planting material, increased plant immunity, accelerated plant growth and development, and increased yield [4]. The practical application of MPP technologies in crop production is constrained by the lack of technical solutions that ensure compliance with processing modes in the field. In this regard, carrying out research and development work to substantiate the technical characteristics of machines and specialized equipment and to identify the optimal modes of plant MPP in industrial horticulture is an urgent task.

${ }^{*}$ Corresponding author: alexeykutyrev@gmail.com 


\section{Materials and Methods}

The use of the developed mounted unit in the technology of cultivation and care of strawberries will allow the processing of berries with a low-frequency pulsed magnetic field with the ability to automatically maintain the required value of magnetic induction in the processing area. Theoretical studies were carried out using the laws and methods of theoretical mechanics, mathematics, and modern methods of computer modeling and programming. Experimental data processing and computer modeling were carried out using CAD software Autodesk fusion 360, Elcut Professional 6.3, Coil 32. The study of the influence of the magnetic field on the growth and yield of agricultural crops is devoted to the work of many authors. The results of the conducted studies show that a weak magnetic field is an environmentally significant factor for plants and is implemented at different stages of plant development and growth, determining its life cycle. As a result of the analysis of the conducted studies and the instrument and hardware base of the MPP of garden plants, it was determined that the equipment of the automated unit should provide a magnetic induction value in the processing zone of 0.1-15 MT, a frequency range of 1-100 $\mathrm{Hz}$, a duty cycle range of 1-100. It is established that the considered samples of technical means for MPP of plants in the field have a number of significant disadvantages: they do not have the ability to adapt the working bodies (magnetic inductors) to the height of plants and row spacing, are intended only for processing low-growing crops horizontally to the soil, do not have the ability to change the angle of inclination of the working bodies, do not have the ability to maintain a given position during work between the working bodies and the processed crops, which ultimately affects the quality of the technological operation. The analysis of the agrophysical properties of the strawberry culture, cultivation schemes is carried out. When developing an automated MPP unit, it is necessary to take into account the size indicators of bushes and their structure, as well as the technology of cultivating strawberries. As a result of the analysis of literature sources and field measurement, the agrotechnological model of the bush is calculated. It is established that when developing an automated unit, it is necessary to take into account the parameters of plants within the following limits: the width of the bush in strawberries varies from 34,5 to $64,2 \mathrm{~cm}$ with an average value of $49,3 \mathrm{~cm}$. The width of the base of the bush is in the range from 18,5 to 41 $\mathrm{cm}$, the average value is $29,7 \mathrm{~cm}$. The height of the bushes is in the range from 22 to 45.5 $\mathrm{cm}$ with an average value of $33,75 \mathrm{~cm}$. The height of the soil shaft under the rows of strawberries depends on many factors and varies from 6,5 to $10 \mathrm{~cm}$ with an average value of $8,25 \mathrm{~m}$.

As a result of the conducted research, the design and technological schemes of the automated unit for the operation of magnetic pulse processing of garden plants were developed. When designing, the possibility of using a mounted automated MPP unit on strawberry plantings in industrial intensive garden plantings, shrubby and low-growing berry fields was taken into account (Fig. 1). 


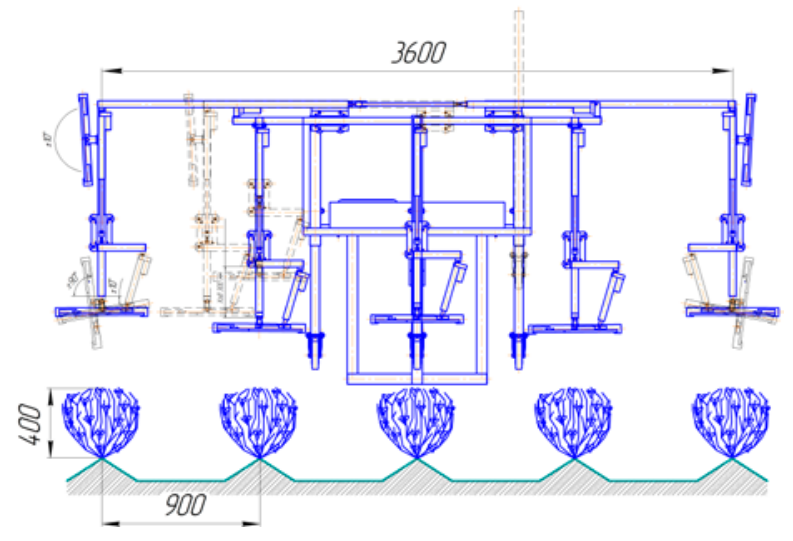

Fig. 1. The scheme of application of the automated mounted unit for MPP of strawberry

The analysis of the schemes of technological application of the automated MPP unit on strawberry plantations and various garden crops showed that the unit should have an adjustable working width in the range of $1,6-3,6 \mathrm{~m}$, the ability to adjust the tilt of the working bodies in the ranges of 0-90, which allows it to be used on plantings of lowgrowing berry trees with a row spacing of $0,3-1,5 \mathrm{~m}$, in intensive gardens with row spacing of 3,0-3,5 $\mathrm{m}$ and shrub berry fields with row spacing of 2,5-3,5 $\mathrm{m}$.

To develop the working bodies of the unit, to create the necessary value of the pulsed magnetic field in the plant irradiation zone, using the Elcut 6.3 Professional CAE software package, computer modeling of several types of inductors with different parameters (crosssectional area, number of turns, winding pitch, inner and outer diameter) was carried out. The analysis of the magnetic field distribution showed that the most suitable is the use of a flat spiral coil of 48 turns of a single-core cable with a cross section of 2,5 $\mathrm{mm}^{2}$ with an outer diameter of $400 \mathrm{~mm}$, an inner diameter of $30 \mathrm{~mm}$, and an inductance of $373 \mu \mathrm{gn}$. The numerical value of the magnetic field induction at a distance of $100 \mathrm{~m}$ from the center of the coil is $5,06 \mathrm{mT}$.

A 3D model of a mounted automated MPP unit has been developed (Fig. 2).

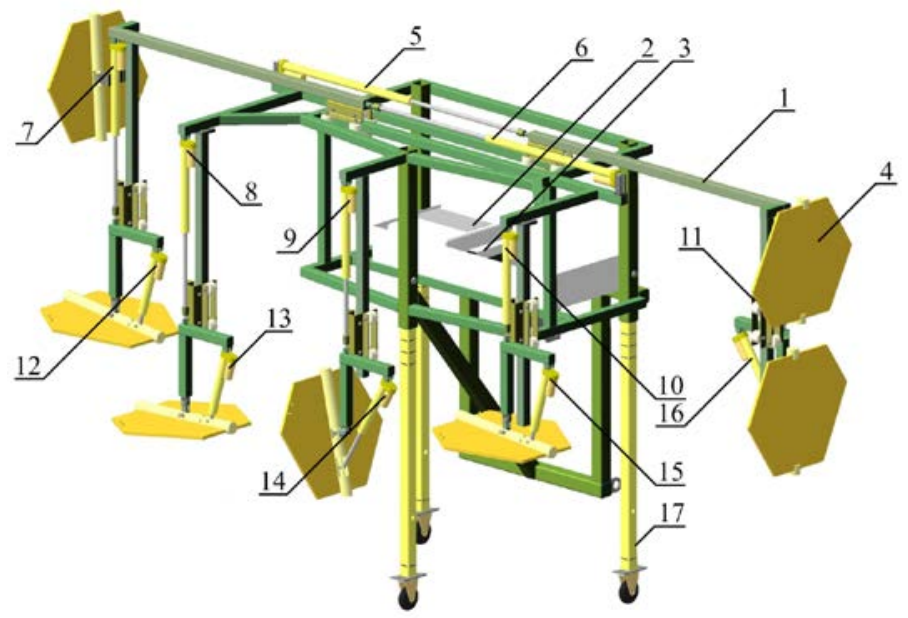

Fig. 2. 3D model of an automated unit for magnetic-pulse processing of strawberries: 1 - frame of the MPP unit; 2 - device for MPP plants; 3 - inverter; 4 - working bodies (magnetic inductors); 5, 6 electric cylinders for changing the working width of the unit; 7, 8, 9, 10, 11 - electric cylinders for maintaining a given distance between inductors and plants; 12, 13, 14, 15, 16 - electric cylinders for changing the angle of inclination; 17 - removable wheels 
To maintain the required magnetic induction value in the impact zone, the unit design provides for the possibility of changing the position of the working bodies in the vertical and horizontal planes. The use of linear actuators with parameters that provide a change in the width of the gripper up to 3,6 m of the rods of the unit weighing up to $500 \mathrm{~N}$, lifting and lowering of the working bodies weighing up to $300 \mathrm{~N}$ by $300 \mathrm{~mm}$, changing the angle of inclination of the inductors up to 90 with a given speed is justified. The developed algorithm of the system of adaptation of the MPP unit allows you to adjust the position of the working bodies depending on the unevenness of the soil surface and the agrophysical parameters of the bushes.

The required distance to the MPP object is controlled by ultrasonic sensors by continuously measuring the distance to the treatment object by capturing the generated narrowly focused signal with a frequency of $40 \mathrm{kHz}$ reflected from the plant. The readings of all sensors are transmitted to the microcontroller, where the required movement of the linear actuator rods is calculated.

To maintain the required value of magnetic induction in the working area and highquality processing of plants, the actuators automatically adjust the working bodies of the unit to the irregularities of the agrophone and agrotechnological parameters of plants, taking into account the size parameters of the bushes, their structure, as well as the size characteristics of the row spacing and rows of various varieties by moving the actuator rod by the value of $\Delta \mathrm{S}$ and the angle of inclination of the inductors (Fig. 3).

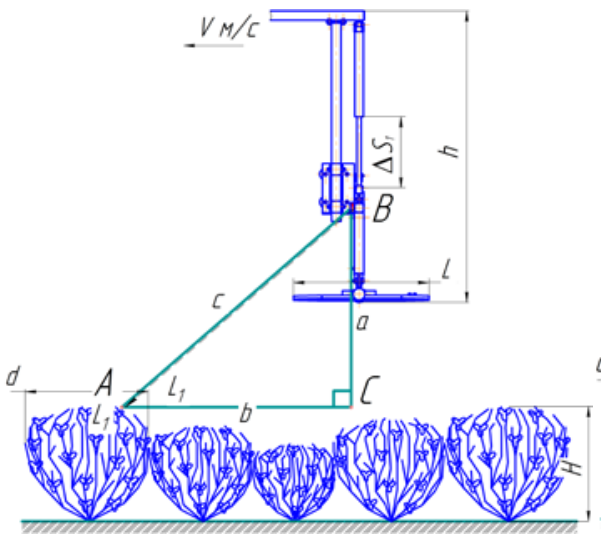

a

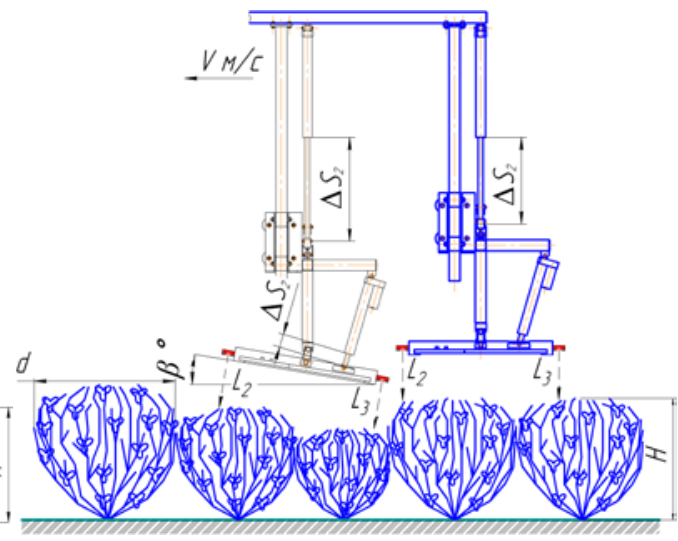

6

Fig. 3. The principle of operation of the system for adapting the working bodies of the automated mounted unit for magnetic pulse treatment of plants: a-scheme for adjusting the magnetic inductors of the automated MPP unit to the height of the strawberry garden; b-scheme for changing the angle of inclination of the magnetic inductors of the automated MPP unit

The delay time for adjusting the working bodies to the plants, depending on the selected operating mode of the MPP unit, is determined by the formula:

$$
\mathrm{T}=\mathrm{c} \cdot \cos (\mathrm{A}) \cdot \mathrm{N} / 3,6\left(\mathrm{~L}_{\mathrm{n}}+\mathrm{d}\right) \mathrm{F}_{\mathrm{c}}
$$

where $\mathrm{c}-$ is the reading of the ultrasonic sensor, $\mathrm{m}, \mathrm{N}$ - is the number of acting magnetic induction pulses, $L_{n}$ - is the length of the flat inductor of the working body in the direction of movement of the unit, $\mathrm{m}, \mathrm{d}-$ is the diameter of the plant bush, $\mathrm{m} ; \mathrm{F}_{\mathrm{c}}-$ is the repetition frequency of the magnetic induction pulses, $\mathrm{Hz}$. 


\section{Results and Discussion}

As a result of the conducted research, an automated unit for magnetic pulse processing of strawberries was developed. The production check of the operability of the automated unit with the system of adaptation of working bodies was carried out on an industrial strawberry plantation with a planting scheme of $80 \times 20$ (Fig. 4).

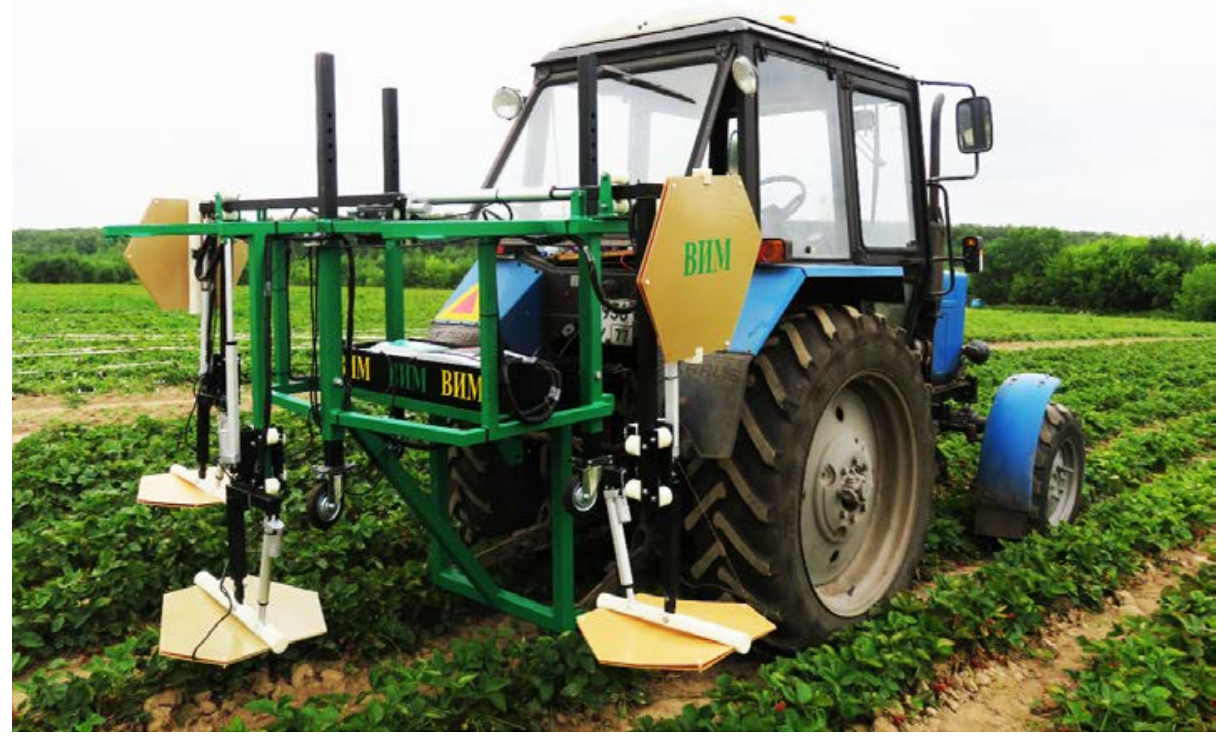

Fig. 4. Implementation of the technological operation of the MPP strawberry automated unit

As a result of the conducted field experiment, a graph of the deviation of the position of the working surface of the magnetic inductors from the required distance is constructed (Fig. 5).

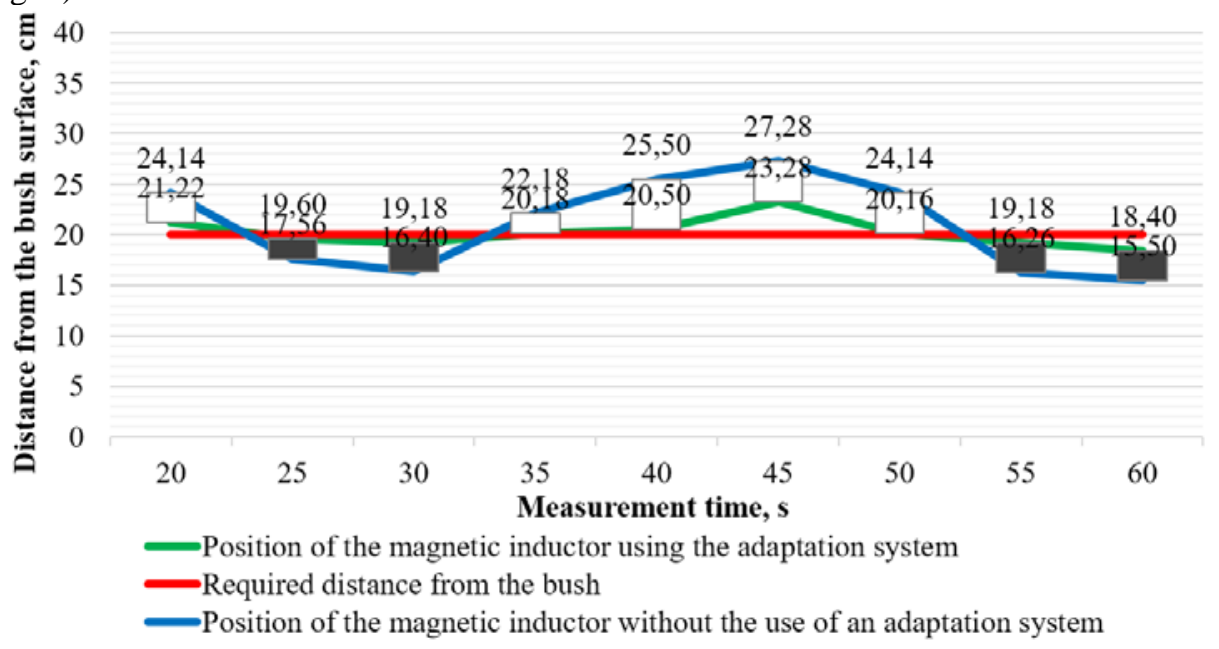

Fig. 5. Fragment of the graph of the deviation of the magnetic inductor from the required distance when the automated unit performs the technological operation of MPP in the field

According to the results of the calculation, the maximum and minimum distances between the working organs of the unit and the plants, the range of variation, the average 
linear deviation, the standard deviation, the variance, the coefficient of variation and oscillation are determined (Table 1).

Table 1. Results of the analysis of the obtained data of the field experiment

\begin{tabular}{|c|c|c|}
\hline Indicator of variation & $\begin{array}{c}\text { Using an automatic } \\
\text { adaptation system }\end{array}$ & $\begin{array}{c}\text { Without using an } \\
\text { automatic adaptation } \\
\text { system }\end{array}$ \\
\hline Maximum, cm & 23,9 & 29,5 \\
\hline Minimum, cm & 16,1 & 13,1 \\
\hline Range of variation, cm & 7,8 & 16,4 \\
\hline Average linear deviation, cm & 1,22 & 3,61 \\
\hline $\begin{array}{c}\text { Variance for the general } \\
\text { population, } \mathrm{cm}^{2}\end{array}$ & 2,42 & 18,69 \\
\hline Sample variance, cm ${ }^{2}$ & 2,48 & 19,17 \\
\hline Standard deviation general, cm & 1,56 & 4,32 \\
\hline $\begin{array}{c}\text { Standard deviation of the sample, } \\
\text { cm }\end{array}$ & 1,58 & 4,38 \\
\hline Coefficient of variation & $8 \%$ & $20 \%$ \\
\hline Oscillation coefficient & 0,38 & 0,75 \\
\hline
\end{tabular}

The analysis of the experimental results showed that the range of variation of the obtained data, when using an automated system for adapting working bodies, is 2,1 times less than when the system is disabled. The coefficient of variation when using the system of adaptation of working bodies is $8 \%$, with the system disabled $20 \%$. A decrease in the coefficient of variation characterizes an increase in the uniformity of the magnetic induction distribution in the processing zone by up to 2,5 times. The use of an automatic system ensures the accuracy of the MPP process operation with a general variance of 2,42.

\section{Conclusions}

For carrying out the technological operation of magnetic-pulse processing of strawberries in the conditions of an industrial plantation, it is recommended to use the automated unit developed in the framework of these studies in the established modes. The unit includes a device for magnetic pulse treatment of plants, magnetic inductors, a control unit for the system of adaptation of working bodies and a program for controlling operating modes. As a result of field studies, it was found that in order to obtain the required value of magnetic induction in the processing zone at a pulse repetition frequency from 1 to $64 \mathrm{~Hz}$ and a magnetic induction of $0,3-15 \mathrm{mT}$, it is necessary to ensure a distance between the working organs and plants from 10 to $250 \mathrm{~mm}$. The numerical value of the magnetic field induction of the working bodies of the unit at a distance of $100 \mathrm{~mm}$ from the center of the coil is 5 $\mathrm{mT}$. The required design parameters of the unit that allow for magnetic pulse processing on strawberry plantings with a row spacing of $0,3-1,5 \mathrm{~m}$ are determined: the width of the gripper, adjustable 1,6-3,6 $\mathrm{m}$, the tilt adjustment of the working bodies in the vertical direction from 0 to 90 .

The use of a mounted automated unit for magnetic-pulse processing of plants in industrial plantations will allow us to continue further scientific research on the use of digital technologies and technical means with intelligent control systems, to accumulate and systematize experimental data on the assessment of the influence of various modes of lowfrequency pulsed magnetic field on plant objects in horticulture. 


\section{References}

1. A. Esitken, M. Turan Alternating magnetic field effects on yield and plant nutrient element composition of strawberry (Fragaria $\mathrm{x}$ ananassa cv. Camarosa), Acta Agriculturae Scandinavica, 54, pp 135-9 (2004)

2. I.G. Smirnov, D.O. Khort, R.A. Filippov, A.I. Kutyrev Factor analysis of irradiation of the strawberries (fragaria $\times$ ananassa) seeds pulsed low-frequency magnetic field, Indian Journal of Agricultural Sciences, 89, 5, pp 113-118. (2019)

3. A.Y. Izmailov, I.G. Smirnov, D.O. Khort, R.A. Filippov, A.I. Kutyrev Magnetic-pulse processing of seeds of berry crop Research in Agricultural Engineering, 64, 4, pp 181186 (2018)

4. M. G. Baryshevand, S.S. Dzhimak Investigation of the influence of a low-frequency electromagnetic field on biological objects. Krasnodar: Kuban state University, pp 1-15 (2012)

5. Chao L., Walker D.R. Effect of magnetic field on germination on apple, apricot and peach seed. HortSci, 2, pp 152-153. (1967) 